\title{
ANTROPOCENO E MUDANÇAS GEOMORFOLÓGICAS: SISTEMAS FLUVIAIS NO PROCESSO CENTENÁRIO DE URBANIZAÇÃO DE SÃO PAULO
}

Cleide RODRIGUES

Isabel Cristina MOROZ-CACCIA GOUVEIA

Rodolfo Alves da LUZ

Yuri VENEZIANI

Iury Tadashi Hirota SIMAS

Juliana de Paula SILVA

\begin{abstract}
RESUMO
Este artigo reúne resultados de pesquisas nas quais a abordagem da Antropogeomorfologia, a Geomorfologia do Antropoceno, foi aplicada, testada e desenvolvida, buscando identificar e dimensionar mudanças geomorfológicas ocorridas no processo centenário de urbanização da região metropolitana de São Paulo. Foram especialmente considerados intervalos históricos de aproximadamente um século ou menos, sistemas fluviais e flúvio-lacustres e geoindicadores, obtidos por estudos de caso, com diferentes recortes geográficos e escalas espaço-temporais. Por meio da metodologia utilizada comprovou-se a possibilidade de identificação de mudanças quanto à sua origem, se antrópica ou não, ou de origem complexa, assim como a possibilidade de mensuração de sua magnitude. A maior parte das mudanças observadas, sejam morfológicas, sedimentares, erosivas ou de balanços e taxas de processos, foram consideradas de alta magnitude para intervalos decadais ou centenários. Em sistemas preservados, mudanças deste tipo tendem a ocorrer em milhares ou centenas de milhares de anos. A magnitude das mudanças geomorfológicas observadas ajuda a caracterizar a necessidade de ampliação e de consideração dos estudos de Ciências da Terra nas atuais discussões sobre o Antropoceno, bem como na direção de uma participação efetiva dessa área do conhecimento no ordenamento do território e na busca de parâmetros para ampliação da resiliência dos sistemas físicos da superfície terrestre.
\end{abstract}

Palavras chave: Antropogeomorfologia; Antropoceno; Sistemas fluviais urbanos.

\section{ABSTRACT}

ANTHROPOCENE AND GEOMORPHOLOGICAL CHANGES: FLUVIAL SYSTEMS IN THE CENTENARY URBANIZATION PROCESS OF SÃO PAULO. This paper presents the results of studies in which the Anthropogeomorphological approach, i.e. the Anthropocene Geomorphology, was adopted, tested, and developed, aiming to identify and measure geomorphological changes that occurred in the centenary urbanization process of the metropolitan region of São Paulo. Intervals in history of about a century or less were especially considered, as well as fluvial and fluvial-lacustrine systems, and geoindicators. The results were obtained for different case studies, in different areas and at different spatio-temporal scales. Based on the methodology used, it was possible to identify changes in origin, which can be anthropic, non- anthropic, or complex, and to measure their magnitude. Most of the observed changes - morphological, sedimentary, or erosional - and their rates and balances were considered to be significant for ten-year or hundred-year intervals. These changes 
tend to occur in thousands or hundreds of thousands of years in natural systems. The high magnitude and velocity of the geomorphological changes indicate that different branches of Earth Science should be considered in current discussions about the Anthropocene, as well as in decision-making regarding environmental planning, and in determining the parameters to increase the resilience of physical systems of the Earth's surface.

Keywords: Anthropogeomrophology; Anthropocene; Urban Fluvial Systems.

\section{INTRODUÇÃO}

Este artigo considera o potencial de colaboração da Geomorfologia para a discriminação da especificidade dos processos da superfície terrestre no Antropoceno e seus estágios, ou seja, em intervalos históricos recentes nos quais as atividades antrópicas parecem comandar grande parte desses processos em termos de balanços, magnitude, taxas, tendências espaciais e vetores (STEFFEN et al. 2007). Por outro lado, também reúne pesquisas nas quais a abordagem da Antropogeomorfologia, a Geomorfologia do Antropoceno, foi aplicada, testada e desenvolvida especialmente para o dimensionamento de mudanças geomorfológicas ocorridas no processo de urbanização de São Paulo, em intervalos históricos de aproximadamente um século ou menos.

Discute-se o potencial de colaboração destes estudos em dois sentidos: na definição de parâmetros para a mensuração das intervenções antrópicas diretas e de seus efeitos em sistemas geomorfológicos, e para a própria discriminação de processos superficiais, se originários de balanços naturais, antropogênicos ou ambos. A metodologia básica para tais enfrentamentos é apresentada em grandes linhas, bem como parte dos resultados da aplicação dos procedimentos, sistemas referenciais e métricas selecionadas.

Todos os geoindicadores trabalhados foram obtidos por estudos de caso na região metropolitana de São Paulo que adotaram as mesmas orientações metodológicas, mas com diferentes recortes geográficos e escalas espaço-temporais e conforme proposições de RODRIGUES (1997, 1999, 2004, 2005, 2010, 2015). Foi possível, assim, discriminar mudanças relativas a estágios do Antropoceno, principalmente, o estágio da transição para a denominada 'Grande Aceleração'.

\section{ANTROPOGEOMORFOLOGIA, ANTROPOCENO E MEGHALAYANA: ALGUMAS CONSIDERAÇÕES INICIAIS}

A necessidade de considerar as intervenções humanas diretas na paisagem e em sistemas geomorfológicos não é algo recente, porém, é nas últimas quatro décadas que a noção de finitude de recursos naturais ganha espaço em fóruns científicos, bem como a aceitação da interferência antropogênica na escala planetária, o que pode explicar o incremento de estudos associados a essas preocupações nestas últimas décadas.

Autores dedicados ao histórico de construção desta temática de pesquisa, denominada de Antropogeomorfologia (THOMAS 1956, BROWN 1970, NIR 1983, JAMES \& MARCUS 2006, GOUDIE 2013, GOUDIE \& VILES 2016, dentre outros), demarcam a segunda metade do século XIX como o início sistemático dessa linha de investigação. Em função da suspeita inicial, posteriormente confirmada, de que o Sistema Terra já teria sido afetado em seus ciclos e balanços na escala planetária devido aos agentes antropogênicos, estudiosos de diversas linhas e campos de investigação vêm se debruçando sobre este tema nas últimas quatro décadas. Estes estudos têm procurado desvendar o significado e a magnitude das interferências antrópicas, sua natureza cumulativa ou sistêmica, e em suas diversas escalas, das locais às regionais e às globais (TURNER et al. 1990).

A obra de George Perkins Marsh, de 1864, divulgada com a publicação denominada 'Man and Nature', é considerada como o primeiro estudo de natureza abrangente a ser publicado na língua inglesa e a considerar os efeitos de diferentes modalidades de intervenções antrópicas em processos superficiais terrestres e suas taxas e balanços (GOUDIE \& VILES 2016). A partir de então diversos estudos têm sido realizados na linha da antropogeomorfologia e podem ser englobados em três grupos. Um primeiro grupo é o de estudos focados em modalidades de intervenção e sistemas 
geomorfológicos, incluindo tipos de desmatamentos, a urbanização em diferentes contextos morfoclimáticos, tipos de atividade pastoril, as diversas e persistentes intervenções agrícolas, as diversas modalidades de mineração ou efeitos em sistemas fluviais. Um segundo grupo de estudos dedicados a questões de natureza metodológica, conceituais, terminológicas e a sistemas de classificação, bem como ao desenvolvimento de critérios, parâmetros, indicadores, métricas e escalas temporo-espaciais para o reconhecimento da natureza e da magnitude dos efeitos dessas intervenções e de suas conexões escalares. Há ainda o terceiro grupo de estudos que focalizam técnicas analíticas e de representação, buscando acurácia e adequação à classificação das superfícies e de seus níveis de mudança, derivação ou perturbação antrópica. O conjunto aqui analisado localiza-se nesses três grupos, e são considerados principalmente os geoindicadores gerados em termos de avaliação da magnitude das intervenções antrópicas e parte de seus efeitos.

Numa outra frente de trabalho cientistas da Terra vêm buscando suas próprias definições e demarcações temporais do Antropoceno, apontando a potencialidade e a operacionalidade dessas referências (PAVLOV 1922 apud GOUDIE \& VILES 2016, CRUTZEN 2002, STEFFEN et al. 2004, ZALASIEWICZ et al. 2011, dentre outros). STEFFEN et al. (2007) apresentam as principais referências aqui adotadas. Estes autores propõem que nos últimos 300 anos teríamos passado do Holoceno ao Antropoceno e, nesse sentido, identificam três estágios relevantes: o Estágio 1, de 1800 a 1945, denominado 'Era Industrial'; o Estágio 2, de 1945 a 2015, denominado 'A Grande Aceleração'; e o estágio 3, que seria o de gerenciamento para ações de recuperação, remediação ou renaturalização. Apesar de existir alguma falta de sincronia entre os diversos países e regiões dentro dessa subdivisão temporal, devido às suas diferentes posições na história da economia mundial, essa subdivisão é amplamente aceita, principalmente no que se refere à demarcação da 'Grande Aceleração' (GOUDIE \& VILES 2016).

Nessa mesma direção, de demarcação temporal e de nomenclatura, mas explorando-se os rígidos critérios de depósitos estratigráficos sincrônicos e generalizados na superfície terrestre, pesquisadores da ICS (International Commission on Stratigraphy) da IUGS (International Union of Geological Sciences) propuseram em julho de 2018 uma subdivisão do Holoceno, baseada em descontinuidade isotópica de átomos de oxigênio em camadas de uma estalagmite na caverna de Mawmluh, no estado de Meghalaya (nordeste da Índia). As mudanças isotópicas seriam consequências de mudanças climáticas globais, que, no caso indiano, seria reflexo do enfraquecimento de atividade das monções, com taxas de redução de chuvas de 20 a $30 \%$ (AMOS 2018). É também proposta a manutenção e a subdivisão da Época Holoceno em três diversos estágios/idades, a saber: a Groelandiana (11.700 - 8.326 AP), a Nortegripiana (8.326-4.250 AP) e a Meghalayana (desde 4.250 AP) (IUGS 2018).

Mesmo dentre os propositores da subdivisão oficial do Holoceno da ICS/IUGS, a sugestão parece ser a da continuidade à utilização das subdivisões dos estudiosos do Antropoceno, tendo em vista que estes fundamentam-se mais na busca de critérios focados em identificar mudanças ambientais exclusivamente de origem antrópica, diferentemente dos estratigráficos. Desta maneira, considerar o Antropoceno e suas subdivisões (STEFFEN et al. 2007) tem sido mais operacional para a discriminação das derivações antropogênicas, principalmente as ocorridas a partir de meados do século XIX.

Essas mudanças antropogênicas recentes caracterizam-se por serem mais velozes, de alta diversidade, apresentando, ao mesmo tempo, sincronicidade numa escala temporal de séculos ou milênios e diacronicidade em escalas temporais de menor intervalo, como os decadais, necessitando de maior liberdade de utilização e teste de critérios para as demarcações de mudanças derivadas das ações antrópicas. Os critérios diversos mais experimentados e utilizados para demarcação do Antropoceno encontram suporte em perspectivas ecológicas, como a da perda de biodiversidade; ou em perspectivas geomorfológicas, como a avaliação da magnitude de processos superficiais erosivos e não apenas deposicionais; na perspectiva subatômica, como a dos marcadores de isotópicos humanos (incluindo-se os TENR-technically enhanced natural radioactivity e a AR-artificial radioactivity; MIETELSKI 2010), ou, ainda, na perspectiva da geoquímica da atmosfera, como a do marcador $\mathrm{CO}_{2}$ e sua variabilidade de concentração no Quaternário, no Holoceno e no Antropoceno (STEFFEN et al. 2007).

Levando em consideração tais discussões, os resultados aqui apresentados adotaram a manutenção dessa visão mais abrangente dos estudiosos da temática do Antropoceno e seus estágios ou sub-estágios, principalmente quanto à sua maior ope- 
racionalidade na busca por identificar e dar a medida de profundas mudanças recentes, sejam elas sistêmicas (sistema Terra) ou cumulativas, de expressão local ou regional (TURNER et al. 1990). Esses intervalos temporais mais curtos (históricos), não discriminados na classificação da ICS, são relevantes para identificação de processos mais intensos e agudos no que se refere aos efeitos diretos da ação humana (assinatura antropogênica) nos diversos processos da superfície terrestre e, dentre esses, os geomorfológicos.

Portanto, a referência temporal adotada foi a que envolve a discussão do Antropoceno com sua diversidade de estudiosos e perspectivas disciplinares, tais como as de geógrafos físicos, arqueólogos, geólogos, ecologistas, geoquímicos, geofísicos, biogeógrafos, zoólogos, climatólogos, dentre outros (Figura 1). De qualquer maneira, os estágios mais recentes até hoje identificados por estudiosos do Antropoceno não são incompatíveis com a adoção recente da ICS, mas seriam subdivisões, ou sub-estágios do Meghalaiana.

\section{ANTROPOGEOMORFOLOGIA: BASES METODOLÓGICAS}

A antropogeomorfologia vem se consolidando enquanto conceito cada vez mais usual para definir o subcampo da Geomorfologia voltado para os estudos das ações e dos efeitos antropogênicos em sistemas físicos da superfície terrestre, como é o caso de sistemas de vertentes, de bacias hidrográficas, sistemas costeiros, geleiras, dunas, cursos fluviais, lagos, planícies fluviais, dentre outros. Conforme dito anteriormente, esse campo, mesmo sem ser assim denominado, vem se desenhando na multidisciplinaridade das especialidades de Ciências da Terra, tais como a geologia, a geomorfologia, a pedologia, a hidrologia, a climatologia e a geografia física.

O livro recentemente organizado por GOUDIE \& VILES (2016) traz uma visão de conjunto das principais referências teóricas e temas ligados à abordagem geomorfológica das intervenções humanas em sistemas físicos da superfície ou próximos à superfície. Esses autores também consideram como relevantes os estudos de MARSH (1864), WOEIKOF (1901), THOMAS (1956), GOLOMB \& EDER (1964), JENNINGS (1966), BROWN (1970), TRIMBLE (1974), NIR (1983), SLAYMAKER et al. (2009) e SZABÓ et al. (2010), demonstrando o longo histórico de construção dessa perspectiva analítica. Esses nomes são coincidentes em diversos dos compêndios selecionados que se dedicam a uma visão abrangente do desenvolvimento dos princípios e dos referenciais teórico-metodológicos para a abordagem geomorfológica das intervenções antrópicas e mudanças significativas a ela associadas.

A maior parte das obras de referência, contudo, apresenta basicamente dois conjuntos de enfoques principais. Um deles é o da proposição de temáticas relevantes para a construção dessa leitura (DOUGLAS 1983, NIR 1983, TOY \& HADLEY 1987, SZABÓ et al. 2010). Outro conjunto é o da análise e mensuração dos efeitos das ações antrópicas em sistemas geomorfológicos específicos (THOMAS 1956, GOUDIE \& VILES 1997, GOUDIE 2013).

Do conjunto de referenciais mais amplos para guiar a perspectiva geomorfológica na análise de mudanças antropogênicas é notável a ênfase dada aos efeitos (não intencionais) das ações antrópicas, em detrimento das intervenções diretas e deliberadas e seus aspectos dinâmicos e de natureza específica. Embora essa tendência não seja generalizada, tal como pode ser observado em FELS (1965), BROWN (1970), DOUGLAS (1983), RODRIGUES (1997, 1999), e PRICE et al. (2011), dentre outros, a abordagem aqui tratada parte de orientações metodológicas em que tanto as ações antrópicas, como seus efeitos, são tratados com igual ênfase.

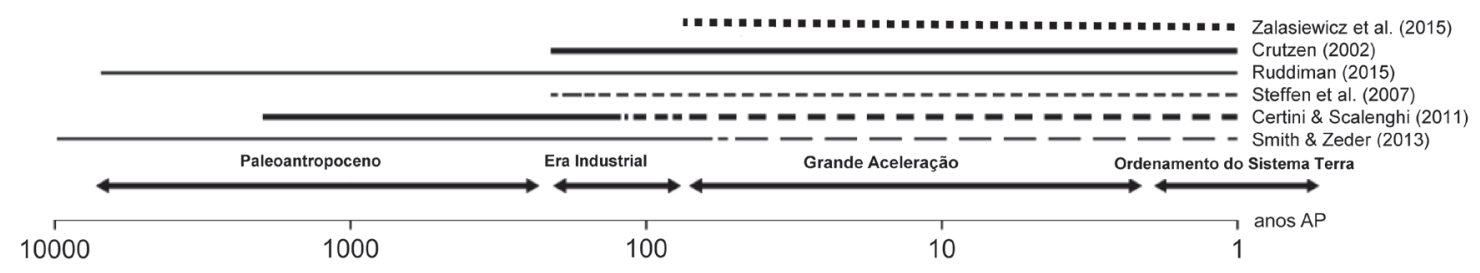

FIGURA 1 - Propostas de demarcação e subdivisão do Antropoceno por autores selecionados. Modificado de GOUDIE \& VILES (2016). 
De forma resumida, a metodologia construída trata de utilização simultânea de alguns princípios e procedimentos, tais como: a radicalização da perspectiva analítica em que as modalidades de intervenções antrópicas são consideradas como intervenções eminentemente geomorfológicas, em especial a da geomorfologia urbana (DOUGLAS 1983; NIR 1983; RODRIGUES 1997, 1999, 2004; GOUDIE \& VILES 2016); a utilização do referencial da abordagem sistêmica em geomorfologia (CHORLEY \& KENNEDY 1971, SCHUMM 1977, dentre outros), o uso de diversas escalas espaciais e temporais para testes e discriminação de métricas (BRUNSDEN 1996); a abordagem dos três níveis de conhecimento geomorfológico (formas, materiais e processos) (HART 1986); o uso dos geoindicadores de forma associada a sistemas geomorfológicos, em nosso caso, fluviais e flúvio-lacustres (BERGER 1996, RODRIGUES \& COLTRINARI 2004, RODRIGUES 2010); a utilização da abordagem histórica e da pesquisa arquivística em geomorfologia (HOOKE \& KAIN 1982, GURNELL et al. 2003, TRIMBLE 2008, dentre outros); a utilização da cartografia geomorfológica retrospectiva e evolutiva (retroanálise da intervenção antrópica) com conteúdos da antropogeomorfologia (morfologia original e antropogênica), tal como em RODRIGUES \& COLTRINARI (2004); a identificação de unidades de morfologia complexa (combinações específicas entre a morfologia original e antropogênica); a busca pelo reconhecimento de níveis de perturbação antropogênica, dentre outros procedimentos (RODRIGUES et al. 2012).

Outra diferença da construção metodológica aqui considerada, é a da continuidade de elaboração de testes em áreas de estudo e de aperfeiçoamentos metodológicos a partir de uma modalidade de intervenção antrópica de relevância inquestionável no Brasil e no mundo, que é a urbanização.

Do ponto de vista dos processos de urbanização como processo geomorfológico, além dos estudos de AB'SABER $(1957,2004)$, a principal inspiração das pesquisas aqui apresentadas advém da abordagem precursora e abrangente de DOUGLAS (1983), com sua abordagem sistêmica e até certo ponto metabólica (não naturalizada) da produção da paisagem urbana.

Procedimentos relevantes derivados desses e dos demais princípios anotados em RODRIGUES $(1997,1999,2004)$ viabilizaram a proposição e o uso de geoindicadores e a utilização dessas métricas para a análise de mudanças no Antropoceno e estágios. Assim, são aqui valorizados geoindicadores morfológico-morfométricos (comprimento, declividade, amplitudes topográficas de morfologias, sinuosidade de canais, raio hidráulico, seção transversal de canal, área de sistemas e sub sistemas fluviais, geometria de subunidades de vertentes, dentre outros); de distribuição e da natureza de materiais superficiais (materiais pedológicos, rochas e materiais antropogênicos, reconhecidos e representados gráfica e cartograficamente em seus atributos bi e tridimensionais e considerados seus parâmetros de arquitetura deposicional); e geoindicadores de processos (aumento de superfícies geradoras de escoamento superficial concentrado, mudanças na magnitude das vazões extremas, dentre outros).

Foram utilizados descritores, marcadores e métricas com critérios alternativos aos critérios da estratigrafia (tais como os presentes na discussão do Antropoceno) para a discriminação e avaliação da magnitude das interferências antrópicas recentes na superfície terrestre. Portanto, são priorizadas as evidências geomorfológicas, que têm sido em grande parte negligenciadas pelas discussões de natureza geocronológica, conforme referências propostas por STEFFEN et al. (2007).

A pesquisa explorou o potencial da Antropogeomorfologia na discriminação e dimensionamento de mudanças em sistemas geomorfológicos em intervalos históricos de centenas ou milhares de anos e principalmente das mudanças ainda mais recentes, vinculadas à passagem do primeiro para o segundo estágio do Antropoceno de STEFFEN et al. (2007). A principal modalidade de intervenção considerada é a do processo centenário da urbanização da região metropolitana de São Paulo, e os principais sistemas referenciais de leitura das mudanças observadas e de sua magnitude são sistemas geomorfológicos fluviais tais como: bacias hidrográficas, sistemas flúvio-lacustres, canais fluviais, planícies de inundação e terraços fluviais típicos do meio tropical úmido.

\section{GEOINDICADORES E ESTUDOS DE CASO}

Os geoindicadores analisados sob essa metodologia vêm revelando seu potencial discriminador da origem das mudanças, se ligadas a variáveis independentes naturais (tectônicas e climáticas) ou à variável 'independente' antropogênica e suas derivações (urbanização e suas taxas de im- 
permeabilização, criação de superfícies com escoamento superficial concentrado, morfologia de ruas e novos vetores ou tipos de fluxos, aterros e supressão de sistemas dissipadores de energia de fluxos fluviais, taxas e capacidade de transmissão de condutos, dentre outros). A relevância de se trabalhar com a variável antrópica tem estreita conexão com a possibilidade de mudanças de rumos no âmbito do ordenamento territorial e ambiental, seja no sentido de adaptação, prevenção, recuperação, ou outras ações relevantes, todas elas dependentes e limitadas pelas esferas sociais, políticas e econômicas.
Os estudos de caso (Quadro 1) que geraram dados quantitativos relevantes para a compreensão da magnitude das intervenções antrópicas dirigidas pelos processos de urbanização e seus vetores de expansão, adensamento, verticalização, dentre outros, foram desenvolvidos à luz da metodologia acima citada, e a maioria deles são parte dos projetos de pesquisa apresentados no quadro 2.

Os recortes espaciais e sistemas geomorfológicos fluviais considerados são apresentados na figura 2. A partir desses sistemas geomorfológicos iniciais, foram também considerados subsistemas de cada um desses, tais como: planícies de inundação, terraços, canais fluviais, remansos e outros.

QUADRO 1 - Estudos selecionados para a discussão do Antropoceno.

\begin{tabular}{|c|c|c|c|c|}
\hline $\begin{array}{l}\text { Sistema } \\
\text { geomorfológico }\end{array}$ & $\begin{array}{l}\text { Escala } \\
\text { espacial }\end{array}$ & $\begin{array}{c}\text { Escala } \\
\text { temporal }\end{array}$ & Fonte & Fomento \\
\hline $\begin{array}{l}\text { Região metropolitana } \\
\text { de São Paulo } \\
\text { (RMSP) e Bacia } \\
\text { Hidrográfica do Alto } \\
\text { Rio Tietê (BAT) }\end{array}$ & Regional & $\begin{array}{l}\text { Variável, } \\
\text { inclusive } \\
\text { centenária }\end{array}$ & $\begin{array}{l}\text { BATISTA (2002): Conversa Cartográfica: Processo de expansão ur- } \\
\text { bana na Metrópole Paulistana e unidades geomorfológicas de mé- } \\
\text { dia escala. } \\
\text { RODRIGUES (Ver Quadro 2). }\end{array}$ & $\begin{array}{l}\text { FAPESP e } \\
\text { CNPq }\end{array}$ \\
\hline $\begin{array}{l}\text { Bacia Hidrográfica } \\
\text { do Rio Tamanduateí }\end{array}$ & $\begin{array}{l}\text { Detalhe } \\
\text { e semi- } \\
\text { detalhe }\end{array}$ & $\begin{array}{l}\text { Variável, } \\
\text { inclusive } \\
\text { centenária }\end{array}$ & $\begin{array}{l}\text { MOROZ-CACCIA GOUVEIA (2010): Da originalidade do sítio ur- } \\
\text { bano de São Paulo às formas antrópicas: aplicação da abordagem } \\
\text { da Geomorfologia Antropogênica na Bacia Hidrográfica do Rio Ta- } \\
\text { manduateí, na Região Metropolitana de São Paulo. } \\
\text { MOROZ-CACCIA GOUVEIA \& RODRIGUES (2017): Mudanças } \\
\text { morfológicas e efeitos hidrodinâmicos do processo de urbanização } \\
\text { na bacia hidrográfica do rio Tamanduateí - Região Metropolitana } \\
\text { de São Paulo. }\end{array}$ & $\mathrm{CNPq}$ \\
\hline $\begin{array}{l}\text { Bacia Hidrográfica } \\
\text { do Rio Aricanduva }\end{array}$ & $\begin{array}{l}\text { Semi- } \\
\text { detalhe }\end{array}$ & $\begin{array}{l}\text { Variável, } \\
\text { inclusive } \\
\text { centenária }\end{array}$ & $\begin{array}{l}\text { SIMAS (2017): Análise retrospectiva de inundação na bacia do Rio } \\
\text { Aricanduva, São Paulo. }\end{array}$ & CAPES \\
\hline $\begin{array}{l}\text { Planície fluvial do } \\
\text { Rio Pinheiros }\end{array}$ & Detalhe & 100 anos & $\begin{array}{l}\text { LUZ (2014): Mudanças geomorfológicas na planície fluvial do rio } \\
\text { Pinheiros, São Paulo (SP), ao longo do processo de urbanização. } \\
\text { LUZ \& RODRIGUES (2015): Anthropogenic changes in urbanised } \\
\text { hydromorphological systems in a humid tropical environment: river } \\
\text { Pinheiros, Sao Paulo, Brazil. }\end{array}$ & CAPES \\
\hline $\begin{array}{l}\text { Sub-bacias pareadas } \\
\text { do Rio Guarapiranga }\end{array}$ & Detalhe & 100 anos & $\begin{array}{l}\text { SILVA (2005): Expansão urbana e evolução geomorfológica em } \\
\text { remansos de reservatórios: análise comparativa de duas bacias } \\
\text { hidrográficas em Guarapiranga, São Paulo. } \\
\text { SILVA \& RODRIGUES (2018): Avaliação histórica de taxas de col- } \\
\text { matagem e sua relação com a evolução da urbanização em bacias } \\
\text { hidrográficas pareadas em Guarapiranga-SP. }\end{array}$ & CAPES \\
\hline $\begin{array}{c}\text { Bacia Hidrográfica } \\
\text { do Córrego Três } \\
\text { Pontes }\end{array}$ & Detalhe & Variável & $\begin{array}{l}\text { VENEZIANI (2014): A abordagem da geomorfologia antropogê- } \\
\text { nica e de modelagens hidrológica e hidráulica na bacia do córrego } \\
\text { Três Pontes (SP) para determinação de picos de vazão e da vulnera- } \\
\text { bilidade a inundações. }\end{array}$ & $\begin{array}{l}\text { FAPESP } \\
2011 / 16396-5\end{array}$ \\
\hline
\end{tabular}

QUADRO 2 - Projetos de pesquisa associados aos estudos de caso apresentados.

\begin{tabular}{|c|c|c|c|}
\hline Projeto & Coordenação & Período & Órgão de Fomento \\
\hline $\begin{array}{c}\text { Cem Anos de Urbanização e Mudanças Geomorfológicas na Região } \\
\text { Metropolitana de São Paulo }\end{array}$ & \multirow{3}{*}{$\begin{array}{l}\text { Profa. Dra. Cleide } \\
\text { Rodrigues }\end{array}$} & $2003-2010$ & CAPES e CNPq \\
\hline \multirow{2}{*}{$\begin{array}{c}\text { Intervenções Antrópicas e Efeitos Hidromorfodinâmicos em } \\
\text { Sistemas Fluviais Urbanizados de São Paulo em Tempos de } \\
\text { Mudanças Climáticas (2 fases) }\end{array}$} & & 2011-2014 & $\mathrm{CNPq}$ \\
\hline & & $2015-2018$ & $\mathrm{CNPq}$ \\
\hline
\end{tabular}




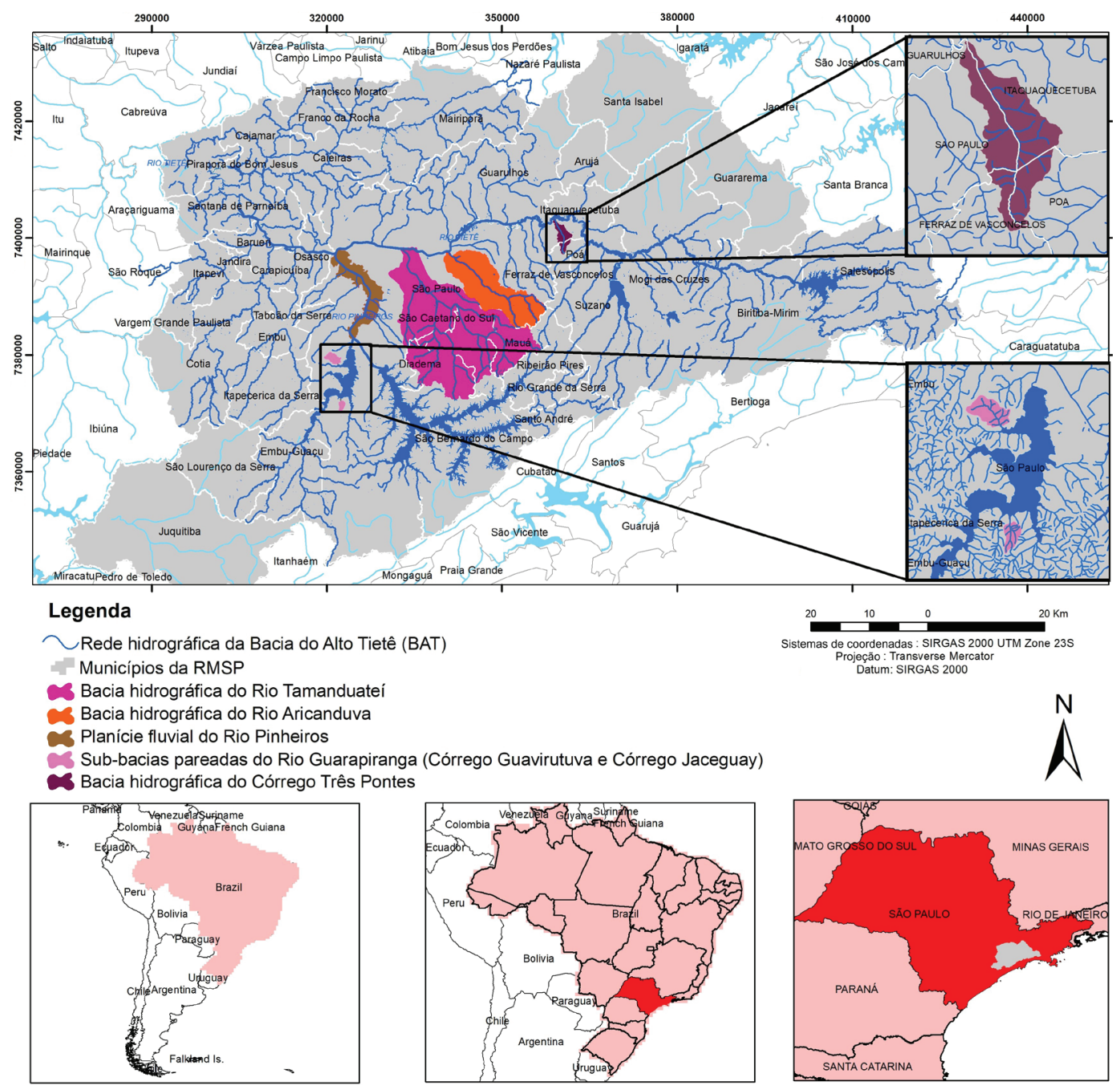

FIGURA 2 - Localização das áreas de estudo.

\section{RESULTADOS E DISCUSSÕES}

A sistematização dos resultados está organizada no quadro 3 , que apresenta os geoindicadores de mudanças de atributos morfológico-morfométricos articulados aos atributos e parâmetros dos materiais superficiais e dos processos, permitindo integrá-los em cenários de reconstituição histórico-geográficas e em leituras diversas da paisagem. Estes geoindicadores são aproveitados especialmente para uma breve avaliação da magnitude dessas mudanças no Antropoceno.

Observando o quadro, já se nota a necessidade procedimental em considerar geoindicadores de intervenções antrópicas diretas (deliberadas) nas paisagens e sistemas associados. Estes geoindicadores são os mais numerosos, com des- taque às mudanças morfológicas observadas em sistemas e subsistemas como canais, planícies de inundação e terraços, além da supressão antropogênica desses.

5.1 Região Metropolitana de São Paulo (RMSP) e Bacia Hidrográfica do Alto Rio Tietê (BAT)

A tabela 1 trata de geoindicadores de mudanças relativos às intervenções urbanas diretas na análise regional obtida por BATISTA (2002) e RODRIGUES $(2004,2006)$, em intervalo temporal de mais de 70 anos. Por meio da sistematização cartográfica de um grande volume de dados e identificação da morfologia original e da morfologia antropogênica de toda a região metropolitana de São Paulo, as autoras correlacionaram a expansão urbana com sistemas ou compartimentos geomor- 
QUADRO 3 - Geoindicadores de mudanças

\begin{tabular}{|c|c|c|c|c|c|c|c|}
\hline $\begin{array}{c}\text { Subsistema e } \\
\text { unidade hidro- } \\
\text { morfológica }\end{array}$ & Parâmetro & Rio & Original & Antrópica & $\begin{array}{l}\text { Variação } \\
\text { absoluta }\end{array}$ & $\begin{array}{l}\text { Variação } \\
\text { relativa }\end{array}$ & Referência Bibliográfica \\
\hline \multirow{28}{*}{ 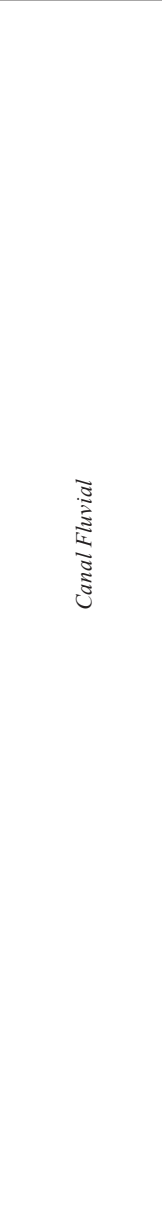 } & \multirow{6}{*}{$\begin{array}{l}\text { Comprimento } \\
\text { do curso princi- } \\
\text { pal }(\mathrm{km})\end{array}$} & Rio Tietê & 100,68 & 53,88 & $-46,80$ & $-46,48 \%$ & Inédito \\
\hline & & Rio Tamanduateí & 39,10 & 36,30 & $-2,8$ & $-7,1 \%$ & MOROZ-CACCIA GOUVEIA 2010 \\
\hline & & Rio Pinheiros & 33,72 & 18,55 & $-15,17$ & $-44,99 \%$ & LUZ 2014 \\
\hline & & Rio Aricanduva & 33,82 & 23,63 & $-10,19$ & $-30,13 \%$ & SIMAS 2017 \\
\hline & & Córrego Três Pontes & 6,92 & 6,70 & $-0,22$ & $-3,18 \%$ & VENEZIANI 2014 \\
\hline & & Ribeirão Guavirutuba & 3,1 & 2,3 & 0,8 & $-25,8$ & SILVA 2005 \\
\hline & \multirow{5}{*}{$\begin{array}{l}\text { Área da seção } \\
\text { transversal }\left(\mathrm{m}^{2}\right)\end{array}$} & Rio Tietê & 135,14 & 568,48 & 433,34 & $420,67 \%$ & $\begin{array}{l}\text { BRITO 1926, DAEE 1998, } \\
\text { CARVALHO } 2006\end{array}$ \\
\hline & & Rio Tamanduateí & - & 64,41 & - & - & DAEE $2012^{1}$ \\
\hline & & Rio Pinheiros & $73,38^{2}$ & $248,9^{3}$ & 175,52 & $239,19 \%$ & EMAE 2009, LUZ 2014 \\
\hline & & Rio Aricanduva & n.s.a. & 96,0 & - & - & Inédito \\
\hline & & Córrego Três Pontes & 25,55 & 38,61 & 13,1 & $51,1 \%$ & VENEZIANI 2014 \\
\hline & \multirow{4}{*}{$\begin{array}{l}\text { Raio Hidráulico } \\
\qquad\left(\mathrm{m}^{2}\right)\end{array}$} & Rio Tamanduateí & - & - & 2,71 & - & DAEE 2012 \\
\hline & & Rio Pinheiros & n.s.a. & 2,8 & - & - & Inédito \\
\hline & & Rio Aricanduva & n.s.a. & 1,5 & - & - & Inédito \\
\hline & & Córrego Três Pontes & 1,7 & 2,25 & 0,55 & $32,4 \%$ & VENEZIANI 2014 \\
\hline & \multirow{4}{*}{$\begin{array}{l}\text { Sinuosidade } \\
\quad(\mathrm{m} / \mathrm{m})\end{array}$} & Rio Tietê & 2,32 & 1,24 & $-1,08$ & $-46,55 \%$ & Inédito \\
\hline & & Rio Tamanduateí & 1,55 & 1,21 & $-0,24$ & $-16,5 \%$ & Inédito \\
\hline & & Rio Pinheiros & 1,88 & 1,00 & $-0,88$ & $-46,81 \%$ & LUZ 2014 \\
\hline & & Rio Aricanduva & 1,75 & 1,22 & $-0,53$ & $-33,33 \%$ & Inédito \\
\hline & \multirow{2}{*}{$\begin{array}{l}\text { Grau de re- } \\
\text { tificação dos } \\
\text { canais }(\mathrm{m})\end{array}$} & Rio Tamanduateí & 701,6 & 64,7 & 636,9 & $9,2 \%$ & Inédito \\
\hline & & Córrego Três Pontes & 28,0 & 4,6 & 23,4 & $83 \%$ & VENEZIANI 2014 \\
\hline & \multirow{7}{*}{$\begin{array}{l}\text { Taxa de desas- } \\
\text { soreamento } \\
\left.\text { ( } \mathrm{m}^{3} / \mathrm{ano}\right)\end{array}$} & Rio Tamanduateí & 30 & 700 & 670 & $2.233,33 \%$ & $\begin{array}{l}\text { DAEE 1998, TRAVASSOS } 2008, \\
\text { MOROZ-CACCIA GOUVEIA } 2010\end{array}$ \\
\hline & & Rio Pinheiros & $150^{1}$ & $280^{4}$ & 130 & $86,67 \%$ & BRITO 1926, LUZ 2014, DAEE 2012 \\
\hline & & Rio Aricanduva & n.s.a. & $70^{5}$ & - & - & DAEE 2012 \\
\hline & & Córrego Três Pontes & 23,05 & 106,1 & 83,05 & $360 \%$ & VENEZIANI 2014 \\
\hline & & Rio Pinheiros & n.s.a. & 200,0 & - & - & EMAE 2009 \\
\hline & & Rio Aricanduva & n.s.a. & 37,5 & - & - & SIMAS 2017 \\
\hline & & Ribeirão Guavirutuba & n.s.a. & 3,8 & - & - & SILVA 2005 \\
\hline \multirow{8}{*}{ 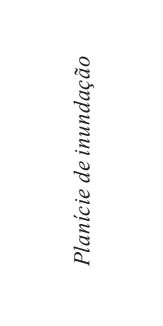 } & \multirow{4}{*}{$\begin{array}{l}\text { Área suprimida } \\
\quad\left(\mathrm{km}^{2}\right)\end{array}$} & Rio Tamanduateí & 44,1 & 4,2 & $-39,9$ & $-90,5 \%$ & MOROZ-CACCIA GOUVEIA 2010 \\
\hline & & Rio Pinheiros & 13,91 & 0,007 & $-13,903$ & $-99,94 \%$ & LUZ 2014 \\
\hline & & Rio Aricanduva & 10,04 & 2,1 & $-7,94$ & $-78,5 \%$ & SIMAS 2017 \\
\hline & & Córrego Três Pontes & 1,503 & 0,376 & $-1,127$ & $-75,0 \%$ & VENEZIANI 2014 \\
\hline & & Rio Tamanduateí & 57,33 & 5,4 & $-51,93$ & $-90,58 \%$ & Inédito \\
\hline & Volume estocá- & Rio Pinheiros & 30,96 & 4,1 & $-26,86$ & $-86,76 \%$ & EMAE 2009, LUZ 2014 \\
\hline & $\left(\mathrm{m}^{3} \times 10^{6}\right)$ & Rio Aricanduva & 20,08 & 4,2 & $-15,88$ & $-78,5 \%$ & SIMAS 2017 \\
\hline & & Córrego Três Pontes & 1,7 & 0,4 & $-1,23$ & $-72,7 \%$ & Inédito \\
\hline & Volume estocá- & Rio Tamanduateí & 75,52 & 6,93 & $-68,9$ & $-90,8 \%$ & Inédito \\
\hline 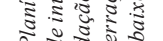 & vel de água & Rio Pinheiros & 90,03 & n.s.a. & n.s.a. & n.s.a. & LUZ 2014 \\
\hline & $\left(\mathrm{m}^{-} \times 10^{\circ}\right)$ & Rio Aricanduva & 39,36 & 6,3 & $-33,06$ & $-83,99 \%$ & SIMAS 2017 \\
\hline & Superfícies & Rio Tamanduateí & 87,2 & 227,2 & 140,0 & $61,6 \%$ & MOROZ-CACCIA GOUVEIA, 2010 \\
\hline$\underset{g}{z}$ & $\begin{array}{l}\text { geradoras de } \\
\text { runoff concen- }\end{array}$ & Rio Aricanduva & 26,5 & 46,86 & 20,36 & $43,44 \%$ & SIMAS 2017 \\
\hline 8 & trado $\left(\mathrm{km}^{2}\right)$ & Córrego Três Pontes & 3,13 & 2,30 & 0,83 & $73 \%$ & VENEZIANI 2014 \\
\hline 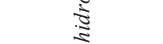 & & Rio Tamanduateí & 79,7 & 9,4 & $-70,3$ & $-88,2 \%$ & MOROZ-CACCIA GOUVEIA 2010 \\
\hline$\widetilde{8}$ & Área permeável & Rio Aricanduva & 102,5 & 28,46 & $-74,04$ & $-72,23 \%$ & SIMAS 2017 \\
\hline 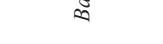 & $\left(\mathrm{km}^{2}\right)$ & Córrego Três Pontes & 9,07 & 1,78 & $-7,29$ & $-80 \%$ & VENEZIANI 2014 \\
\hline & & Ribeirão Guavirutuba & 3,51 & 0,54 & $-2,97$ & $-80,6 \%$ & SILVA 2005 \\
\hline
\end{tabular}

${ }^{1}$ Estação Fluviométrica Pacheco Chaves; ${ }^{2}$ Próximo à ponte Bernardo Goldfarb; ${ }^{3}$ Canal Inferior do Pinheiros; ${ }^{4}$ Vazão para a cota de extravasamento de $718 \mathrm{~m}$ no canal do Pinheiros Inferior (DAEE 2012); ${ }^{5}$ Retirado de DAEE (2012), referente ao trecho com maior recorrência de enchentes; n.s.a. $=$ não se aplica. 
TABELA 1 - Intervenções urbanas diretas em compartimentos geomorfológicos na região metropolitana de São Paulo. Adaptado de RODRIGUES (2004) e RODRIGUES (2005).

\begin{tabular}{|c|c|c|c|c|c|c|c|}
\hline & \multirow{2}{*}{ Unidades Geomorfológicas } & & \multicolumn{5}{|c|}{ Periodos de expansão urbana } \\
\hline & & & Até 1929 & $1929-1962$ & $1963-1997$ & $\begin{array}{c}\text { Demais usos } \\
\text { do solo }\end{array}$ & Total \\
\hline \multirow{4}{*}{ 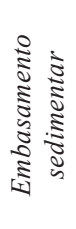 } & \multirow{2}{*}{ Planície de inundação } & $\mathrm{km}^{2}$ & 20,61 & 211,23 & 121,71 & 518,14 & 871,7 \\
\hline & & $\%$ & 2,36 & 24,23 & 13,96 & 59,44 & 100 \\
\hline & \multirow{2}{*}{$\begin{array}{c}\text { Terraços fluviais e colinas } \\
\text { sedimentares }\end{array}$} & $\mathrm{km}^{2}$ & 71,91 & 417,9 & 155,87 & 331,66 & 977,34 \\
\hline & & $\%$ & 7,36 & 42,76 & 15,95 & 33,93 & 100 \\
\hline \multirow{6}{*}{ 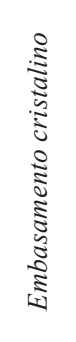 } & \multirow{2}{*}{$\begin{array}{c}\text { "Morros" } \\
\text { Colinas cristalinas }\end{array}$} & $\mathrm{km}^{2}$ & 1,63 & 328,3 & 872,39 & 4348,54 & 5580,85 \\
\hline & & $\%$ & 0,03 & 5,91 & 15,72 & 78,34 & 100 \\
\hline & \multirow{2}{*}{$\begin{array}{c}\text { "Serras" } \\
\text { Rochas graníticas }\end{array}$} & $\mathrm{km}^{2}$ & 0 & 6,77 & 90,13 & 390,65 & 487,55 \\
\hline & & $\%$ & 0 & 1,39 & 18,49 & 80,13 & 100 \\
\hline & \multirow{2}{*}{ Escarpas da serra do mar } & $\mathrm{km}^{2}$ & 0 & 0,41 & 0 & 53,14 & 53,56 \\
\hline & & $\%$ & 0 & 0,77 & 0,01 & 99,22 & 100 \\
\hline & \multirow{2}{*}{ Total } & $\mathrm{km}^{2}$ & 94,15 & 964,62 & 1084,24 & 5310,47 & 7453,47 \\
\hline & & $\%$ & 1,26 & 12,94 & 14,55 & 71,25 & 100 \\
\hline
\end{tabular}

fológicos, interpretadas aqui enquanto transgressão ou supressão de unidades e sistemas geomorfológicos.

Apesar de existirem questões de precisão cartográfica na escala adotada para as estimativas realizadas nessa oportunidade, é possível identificar a ordem de grandeza e a relevância da expansão urbana de alguns intervalos temporais, parte deles coincidente com a subdivisão do Antropoceno de STEFFEN et al. (2007). Dentre algumas das evidências trazidas por esse quadro, estão: a taxa de urbanização de morros cristalinos, que triplica após a década de 1960 , passando de $328 \mathrm{~km}^{2}$ a $872 \mathrm{~km}^{2}$. Essa fase, que na verdade é mais aguda nas décadas de 1970 e 1980 e tem continuidade em décadas seguintes aqui não analisadas, traz combinações morfológicas complexas das mais problemáticas no que se refere à qualidade ambiental urbana (problemas sanitários locais e regionais), à questão de riscos, assim como em relação a processos geomorfológicos (efeitos não intencionais). Apresenta as maiores taxas de escorregamentos urbanos (LIMA 1990) e as maiores taxas de erosão e de sedimentação (LIMA 1990, SILVA 2005, CAMPAGNOLI 2002). Esse quadro é geral na região metropolitana de São Paulo e mais agudo em terrenos cristalinos, e representa, no plano regional, processos antropogênicos (diretos e indiretos) característicos das décadas citadas. São característicos, portanto, do estágio Antropocênico da Grande Aceleração.
Os estudos realizados por RODRIGUES $(2014,2018)$ em escalas regionais e de semi-detalhe, destacaram alguns geoindicadores morfológicos para apreciação do Antropoceno, principalmente em relação às intervenções antrópicas em sistemas e subsistemas de planícies fluviais meândricas na BAT. Um deles é o indicador morfológico de supressão das planícies fluviais, em especial para os subcompartimentos de planícies de inundação. Estimou-se que na BAT perto de $80 \%$ das morfologias originais deste compartimento foram suprimidas definitivamente ao longo do último século, por meio de aterros, represamentos, impermeabilizações ou outras intervenções antrópicas diretas. $\mathrm{O}$ indicador morfométrico 'comprimento de canal principal' para o trecho do Rio Tietê estudado por RODRIGUES $(2014,2018)$, que vai do reservatório de Ponte Nova a Barueri, apresentou uma variação relativa ao longo da última centena de anos de diminuição de $46,48 \%$ pela ação direta de retificações, intensificadas ao longo do estágio da Grande Aceleração. Para o mesmo trecho estudado, acompanha essa mesma tendência o indicador sinuosidade do canal principal, que perde $46 \%$ em relação à sua condição original no período. Na análise documental de CARVALHO (2006) foi observado um incremento de $426,67 \%$ na área da seção transversal do canal do Rio Tietê em área próxima à atual Ponte das Bandeiras (antiga Ponte Grande). 


\subsection{Bacia Hidrográfica do Rio Tamanduateí}

As análises retrospectivas de detalhe efetuadas por MOROZ-CACCIA GOUVEIA (2010) na bacia hidrográfica do rio Tamanduateí, num intervalo temporal de 129 anos (1881-2010), indicam que a ocupação urbana no final do século XIX apropriou-se das planícies de inundação e terraços, apresentando forte incremento após 1929 e avançando sobre os morros cristalinos, sobretudo a partir da década de 50 (período da Grande Aceleração), apresentando fases mais agudas nas décadas de 80 e 90.

Como efeitos indiretos da ocupação urbana, a autora identificou mudanças significativas no comportamento hidrogeomorfológico da bacia hidrográfica, sobretudo em função da geração de superfícies com tendência ao escoamento superficial concentrado. Deve-se ressaltar que tais raciocínios basearam-se apenas em parâmetros morfométricos e morfológicos (geometria e setorização das morfologias originais das vertentes) e na condição de permeabilidade da superfície. No estágio pré-urbano a bacia hidrográfica apresentava, em tese, condições para uma distribuição equilibrada entre superfícies com tendência à infiltração ( $25 \%)$, escoamento superficial difuso (32\%) e escoamento superficial concentrado (26\%), ainda que a tendência à infiltração se apresentasse inferior ao escoamento superficial. Já no quadro atual, a autora verificou que as áreas com tendência ao escoamento superficial concentrado mais do que dobraram, passando para $61 \%$ do total enquanto as áreas com tendência à infiltração sofreram redução, passando a ocupar apenas 3,3\% da área total da bacia hidrográfica. Em relação às áreas com tendência ao armazenamento temporário de vazões de pico (funcionalidade de planícies fluviais), verificou-se uma redução de $90 \%$.

No que se refere às intervenções antrópicas diretas sobre os subsistemas fluviais (indicadores morfomético e sinuosidade), observou-se que, em 2001, mais de $40 \%$ dos canais fluviais da bacia hidrográfica já havia sido alvo de retificações e/ou tamponamentos, sendo que o período que se estende de 1952 a 1983, corresponde aquele de maior intensificação de tais práticas.

No período de análise, o rio Tamanduateí teve $64,7 \mathrm{~km}$ de seu curso retificado, reduzindo seu índice de sinuosidade de 1,55 para 1,21, ou seja, o canal antes considerado meândrico passou a ser levemente sinuoso. Cumpre ressaltar que, embora a partir da década de 50, as intervenções antrópicas em cursos d'água tenham se intensificado, ou seja, no período da 'Grande Aceleração', não se pode negligenciar o fato de que, já no século XIX, modificações relevantes, ainda que restritas, tais como a mudança da localização da foz do rio Tamanduateí e os aterros de planície de inundação, já se verificavam.

De acordo com DAEE (1998), na época do primeiro projeto de canalização na bacia hidrográfica em 1890, a vazão de projeto (vazão de pico considerada) era de $30 \mathrm{~m}^{3} / \mathrm{s}$ na foz do rio Tamanduateí. Atualmente, admite-se que em alguns eventos a vazão pode chegar a $700 \mathrm{~m}^{3} / \mathrm{s}$ (TRAVASSOS 2008). Considerando esses dados de vazão de projeto, pode-se admitir que a vazão máxima extrema na foz do rio Tamanduateí tenha aumentado em torno de 23 vezes ao longo da urbanização da bacia hidrográfica, efeito antropocênico ainda pouco considerado em termos de impactos ou de dimensionamento de obras (MOROZ-CACCIA GOUVEIA \& RODRIGUES 2017).

Os resultados obtidos por MOROZ-CACCIA GOUVEIA (2010) evidenciam também que o aumento de $2.300 \%$ da vazão de projeto (vazão extrema) do rio Tamanduateí não pode ser explicado exclusivamente pelo aumento de $30 \%$ nas precipitações na RMSP identificado por PIVETTA (2012) e SILVA DIAS et al. (2013). Esse acréscimo pode ser atribuído, em grande parte, à impermeabilização antropogênica verificada na bacia hidrográfica (Figura 3), embora as inúmeras canalizações e retificações dos afluentes do rio Tamanduateí, bem como inputs ou entradas de água de outras bacias hidrográficas pelo sistema de abastecimento público também contribuam para esse incremento. Cumpre destacar também, como importante fator de aumento das vazões na foz do rio Tamanduateí, a supressão das planícies de inundação.

\subsection{Bacia Hidrográfica do Rio Aricanduva}

Tratando ainda das mudanças antropogênicas no balanço entre áreas com tendência à infiltração ou ao escoamento superficial concentrado, é interessante destacar estudo de SIMAS (2017), realizado na bacia hidrográfica do rio Aricanduva. Identificou-se um aumento de $43,44 \%$ na área com tendência ao escoamento superficial concentrado em cenário antropizado recente (ano de 2010) comparativamente ao cenário de condições originais restituídas. O ano de 1972 foi adotado como representativo da época de ocupação mais acelerada (Grande Aceleração) 


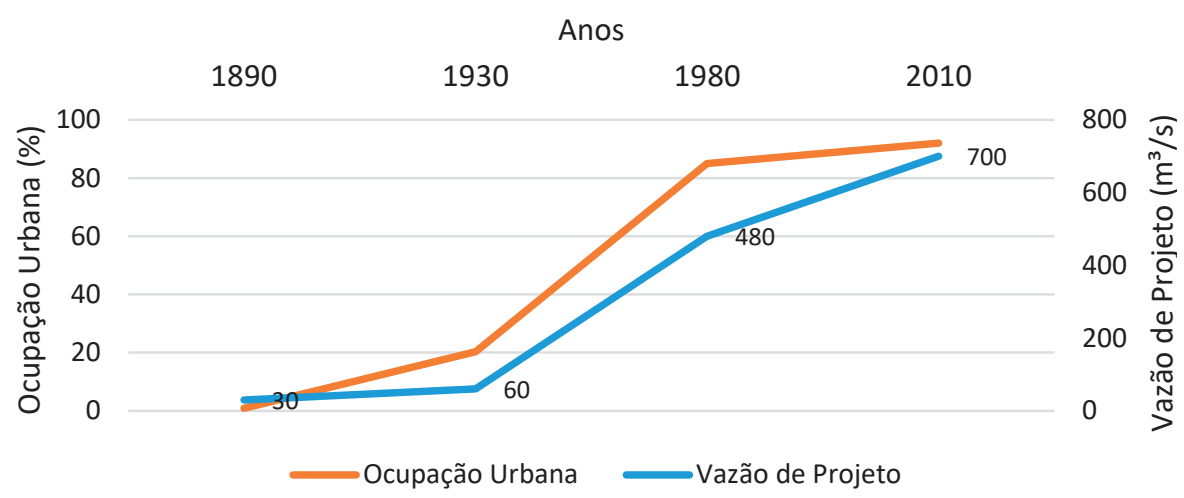

FIGURA 3 - Correlação entre vazão e ocupação urbana na Bacia Hidrográfica do Rio Tamanduateí. Fonte: MOROZ-CACCIA GOUVEIA \& RODRIGUES (2017).

Esta análise permite extrapolar a avaliação para um geoindicador de áreas geradoras de escoamento concentrado para melhor leitura do cenário atual, em que as obras de contenção de cheias, como os canais artificiais e os piscinões, encontram-se inadequados à funcionalidade que visavam substituir. Sua inadequação passa pelo fato que estas obras hidráulicas foram implementadas com base em limiares (como tempo de retorno de vazões de pico) que foram há muito superados. As taxas de impermeabilização atingidas neste período de aceleração antropocênico observado (28 anos) elevaram exponencialmente o volume e velocidade do fornecimento de água das vertentes aos córregos.

Ao mesmo tempo, é preciso considerar que o comprimento do canal do rio Aricanduva foi reduzido em $30,13 \%$, e sua sinuosidade reduzida em $33,33 \%$. Porém, foram suprimidas as áreas onde havia a maior tendência natural para comportar os transbordamentos do rio e amortecer as cheias, o que é possível de se avaliar pelo indicador de redução do volume de água armazenável nos subsistemas planície de inundação e baixos terraços, que apontou uma perda na ordem de $84 \%$ dessa capacidade. A elevada magnitude destas transformações no sistema hidromorfológico condizem com o período da Grande Aceleração do Antropoceno de STEFFEN et al. (2007).

\subsection{Planície Fluvial do Rio Pinheiros}

As transformações na planície fluvial do rio Pinheiros durante os últimos 100 anos foram objeto de investigação de LUZ (2014) e LUZ \& RODRIGUES (2015). Os resultados da pesquisa demonstram os significativos efeitos da ação antrópica relacionada à urbanização nos terrenos de origem fluvial, assim como a elevada magnitude das mudanças na hidrodinâmica dos sistemas fluviais.

Em apenas 21 anos (1936 a 1957), que aqui podemos incluir no período de 'Grande Aceleração', um canal retilíneo substituiu o antigo canal meândrico, em que o comprimento foi reduzido quase pela metade, a profundidade média foi aumentada para um pouco mais da metade e a largura foi aumentada em quase duas vezes.

Um canal fluvial que antes transportava sedimentos finos e matéria orgânica num fluxo de água constante para jusante foi substituído por um canal artificial com fluxo controlado por estruturas de engenharia, que se comporta como uma série de lagos com vazão insignificante que é, por vezes, revertida para montante. Atualmente, a maior parte dos sedimentos e matéria orgânica que chegam ao canal Pinheiros, incluindo os poluentes, são depositados e acumulados em seu leito, sendo necessária a retirada de cerca de $200.000 \mathrm{~m}^{3}$ de material por ano (EMAE 2009).

Durante cerca de 80 anos de urbanização/ Grande Aceleração, as intervenções antrópicas diretas foram responsáveis pela completa remoção do sistema hidromorfológico meândrico original. Os terrenos úmidos da antiga planície de inundação foram drenados, o que permitiu a sua urbanização. Como resultado, não há mais terrenos remanescentes da planície de inundação que poderiam servir como áreas de armazenamento de águas durante as inundações, e que atenuariam os efeitos das descargas de cheia do sistema.

Com a eliminação da planície de inundação, seu antigo nível topográfico tornou-se um nível de terraço baixo por causa das modificações na dinâmica de cheias do canal, agora controlada artificialmente. A disposição de aterros sobre a antiga planície de inundação criou novos níveis de terraços que topograficamente podem ser incorporados aos níveis 
pré-existentes. Aproximadamente $16.280 .000 \mathrm{~m}^{3} \mathrm{de}$ materiais tecnogênicos foram dispostos sobre a antiga planície de inundação e baixos terraços ao longo da urbanização, o que implica diretamente no registro estratigráfico destes eventos.

Assim, agentes antrópicos têm sido responsáveis pela geração ou eliminação de tipos e formas de relevos, eventos que são esperados para ocorrer em escalas temporais de dezenas de milhares de anos em condições naturais. Há ainda as mudanças antrópicas sofridas em toda a bacia hidrográfica do rio Pinheiros, para além da planície fluvial, onde a urbanização, a industrialização, a implementação de sistema viário e os represamentos modificaram as taxas e processos de infiltração nas vertentes e as descargas dos rios afluentes. O input de águas e sedimentos das vertentes e rios afluentes no sistema hidromorfológico da planície fluvial do rio Pinheiros também está significativamente alterado pela ação antrópica.

\subsection{Sub-Bacias Pareadas do rio Guarapiranga}

O estudo de SILVA (2005) traz geoindicadores interessantes tanto para a discriminação da magnitude das ações diretas da urbanização em sistemas geomorfológicos em estágios do Antropoceno, como em relação à magnitude dos efeitos dessas ações em intervalo temporal de aproximadamente 100 anos.

O ribeirão Guavirutuba é o rio principal de uma bacia de terceira ordem afluente da Represa Guarapiranga. Foi realizado um histórico do uso da terra nesta bacia hidrográfica e dos graus de assoreamento no remanso deste rio, de forma a considerar os estágios de urbanização. No período da grande aceleração (1972-1986) houve uma mudança radi- cal na bacia hidrográfica do ribeirão Guavirutuba, passando de uma ocupação predominantemente de média densidade para alta densidade, com processos acelerados de desmatamento, cortes e aterros para construção novas edificações, o que resultou numa redução de $80,6 \%$ da área permeável e gerou uma grande disponibilidade de sedimentos e consequente assoreamento do remanso da represa (Figura 4).

Em SILVA \& RODRIGUES (2018) foi demonstrada a correlação destes dados com outra bacia afluente da Represa Guarapiranga, com predomínio de mata secundária e usos não urbanos (ribeirão Jaceguay). No remanso do ribeirão Guavirutuba o avanço da colmatagem foi de quase $300 \mathrm{~m}, 6$ vezes maior do que no remanso do ribeirão Jaceguay, demonstrando que a bacia hidrográfica do rio Jaceguay possui usos mais compatíveis a uma área de proteção de mananciais de abastecimento público.

\subsection{Bacia Hidrográfica do Córrego Três Pontes}

Em escala de maior detalhe $(1: 10.000)$ o estudo geomorfológico antropogênico da bacia hidrográfica do córrego Três Pontes, na Zona Leste da Cidade de São Paulo, considerou dois cenários como bases de comparação, ambos inseridos no estágio da Grande Aceleração. O primeiro cenário considerado foi o do ano de 1962, a partir do qual os compartimentos geomorfológicos originais ou semi-preservados foram mapeados. O segundo, relativo a 2011, foi o cenário representativo da urbanização consolidada. Os principais geoindicadores de mudanças antropogênicas aqui considerados são referentes às formas nos cursos fluviais

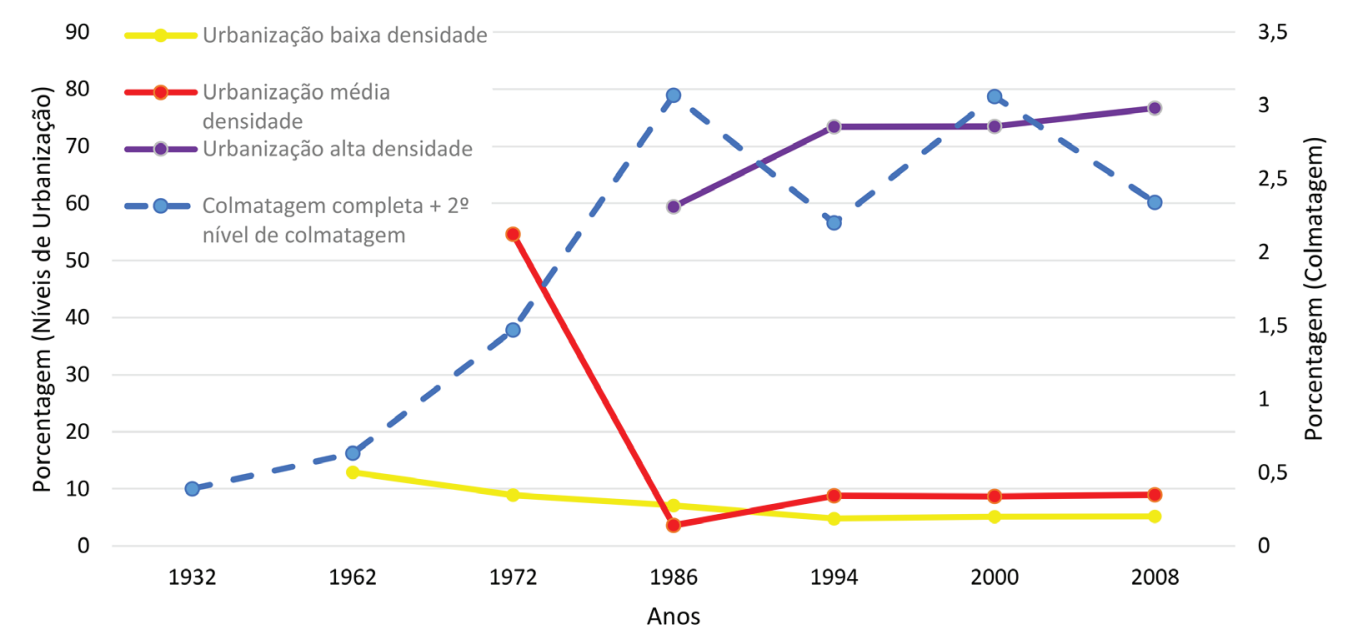

FIGURA 4 - Evolução da Colmatagem (assoreamento) X Evolução dos padrões de urbanização da Bacia do Ribeirão Guavirutuba. Fonte: SILVA \& RODRIGUES (2018). 
(extensão e morfologia), nos materiais que compõe a superfície da bacia hidrográfica, e nos processos decorrentes das mudanças sofridas na superfície desta bacia ao longo do período considerado, destacando-se aquelas observadas nas vazões de pico.

A hidrografia antropogênica mapeada no período pós-urbanização totalizou, aproximadamente, $21 \mathrm{~km}$, dos quais, $15,4 \mathrm{~km}$ perenes e $5,6 \mathrm{~km}$ intermitentes, classificados conforme a tabela 2 .

Um percentual $56,82 \%$ dos cursos fluviais mapeados apresentou modificação de original ou semi-preservado, para antropogênico, dos quais $35,12 \%$ retificados, $3,37 \%$ retificados em concreto e $12,04 \%$ canalizados. Houve conservação de $43,18 \%$ dos cursos d'água analisados no período. Quanto ao rio principal do córrego Três Pontes, em 2011, foram mapeados $6,7 \mathrm{~km}$ de extensão, aproximadamente $300 \mathrm{~m}$ a menos em comparação ao mapeamento de 1962, consequência das retificações identificadas, que derivou novo traçado e perfil longitudinal com declividade de $0,013 \mathrm{~m} / \mathrm{m}$, $7 \%$ superior em comparação à $1962(0,012 \mathrm{~m} / \mathrm{m})$.

As alterações antropogênicas na superfície desta bacia hidrográfica foram de elevado impacto, pela transformação das condições de permeabilidade em intervalo de menos de 50 anos. Entre 1962 (cenário semi-preservado) e 2011, cerca de 75\% da bacia teve o uso da terra transformado de mata ou campo antrópico, para urbano denso, com taxa de ocupação e impermeabilização próxima à $100 \%$. A área permeável da bacia reduziu de $9,07 \mathrm{~km}^{2} \mathrm{em}$ 1962 para $1,78 \mathrm{~km}^{2}$ (diminuição de cerca de $80 \%$ ). Os setores de produção de escoamento concentrado nas vertentes foram particularmente afetados durante esse intervalo: cerca de $75 \%$ das vertentes de domínio concentrador, principais responsáveis pela geração de runoff, foram impermeabilizadas com uso urbano consolidado.

Tal modificação impactou no deflúvio e nas vazões de pico, que em alguns casos mais do que triplicaram. A exemplo, para um evento de 2 horas de duração e tempo de retorno de 5 anos, a vazão original estimada (modelagem hidrológica Ven Te Chow-SCS) saiu de $21,08 \mathrm{~m}^{3} / \mathrm{s}$ para $44,00 \mathrm{~m}^{3} / \mathrm{s}$, representando aumento de 108\%. Quanto maior a magnitude, mais elevada tende a ser esta fração, logo, para evento de 20 minutos de duração e tempo de retorno 2 anos, o aumento foi de $518 \%$ (de $2,52 \mathrm{~m}^{3} / \mathrm{s}$ para $15,57 \mathrm{~m}^{3} / \mathrm{s}$ ).

Com tal mudança sobre a magnitude de vazões, foram realizadas obras hidráulicas no canal principal e tributários que modificaram suas capacidades. No caso do canal principal, no seu terço de jusante, as retificações em concreto produziram alterações no formato, área e demais parâmetros hidrogeométricos da seção transversal. Com as obras levadas a cabo, ela passou de irregular para trapezoidal, aumentando-se sua profundidade e largura, cujas alterações modificaram a área máxima de $25,55 \mathrm{~m}^{2}$ para $38,61 \mathrm{~m}^{2}$. Estimativas de vazões teóricas (ressalva-se que não há monitoramento hidráulico nesta bacia hidrográfica) apontam para aplicação na ordem de 4 vezes a capacidade original em função de tais obras hidráulicas na seção de jusante.

Contudo, pontua-se que tais modificações não foram suficientes para atender as vazões solicitadas em eventos de elevada magnitude (sobretudo acima de 10 anos de tempo de retorno) no terço de jusante, próximo ao canal do rio Tietê, onde, em função da presença de sistemas morfológicos de acumulação de fluxos, como backswamps,

TABELA 2 - Extensão e porcentagem da hidrografia antropogênica na Bacia Hidrográfica do Córrego Três Pontes. Fonte: VENEZIANI (2014).

\begin{tabular}{cccc}
\hline & Aspecto (ou apresentação) & Extensão $(\mathrm{km})$ & Percentagem (\%) \\
\hline \multirow{3}{*}{ Perene } & Original (semi-preservado) & 4,63 & 22,93 \\
& Retificado & 7,09 & 35,12 \\
& Retificado em concreto & 0,68 & 3,37 \\
& Tubulado & 0,55 & 2,73 \\
\multirow{2}{*}{ Intermitente } & Canalizado & 2,43 & 12,04 \\
& Original (semi-preservado) & 4,09 & 20,25 \\
& Tubulado (pluvial subterrânea) & 0,08 & 0,40 \\
\hline Total & Canaleta de drenagem & 0,64 & 3,16 \\
\hline
\end{tabular}


inundações cada vez mais duradouras foram produzidas. Neste sentido, vale ainda pontuar que a planície de inundação do córrego Três Pontes foi suprimida em $75 \%$, ou seja, apenas $0,37 \mathrm{~km}^{2}$ de sua área original de $1,05 \mathrm{~km}^{2}$ permanece em estado próximo ao natural. A elevada vulnerabilidade dos assentamentos urbanos aí presentes, demandaram controles hidráulicos suplementares, como a construção de reservatórios artificiais (piscinão Jardim Romano), com capacidade de armazenamento de $15.000 \mathrm{~m}^{3}$, e obras de desobstrução do leito fluvial, que seguem sendo realizadas no tempo atual.

\section{CONSIDERAÇÕES FINAIS}

Os estudos de caso apresentados demonstram a alta magnitude das transformações ocorridas nos últimos cem anos de urbanização na bacia hidrográfica do Alto Tietê, e em especial, a partir do estágio da Grande Aceleração. As taxas de mudanças identificadas são inquestionavelmente superiores àquelas mudanças geomorfológicas relativas à situação de equilíbrio dinâmico próprio de cada um dos sistemas e sub-sistemas fluviais do meio tropical úmido analisados em sua situação original. Isso é notável mesmo considerando seus setores mais dinâmicos, como é o caso do processo de solapamento de margens côncavas e a avulsão de canais meândricos, que evoluem morfologicamente na escala métrica em intervalos decadais ou centenários.

Nas transformações antrópicas diretas e indiretas observadas em todos os estudos, a escala de cem metros e de quilômetros são alcançadas em apenas algumas décadas por meio da urbanização. Algumas taxas de mudanças colocam-se numa ordem de grandeza equiparável às transformações tectônicas catastróficas ou aos eventos extremos de mudanças climáticas globais, sem necessidade desses processos estarem operando contemporaneamente. O caso de mudança de vazão de pico (vazão de projeto) do rio Tamanduateí, que se amplia 23 vezes, é exemplo contundente da magnitude das mudanças antrópicas no estágio da Grande Aceleração, ainda que consideremos os maiores inputs de ordem climática identificados no período na área de sua bacia hidrográfica. A perda de aproximadamente $80 \%$ de setores geomorfológicos de planícies fluviais com funcionalidades hidrológicas de amortecimento de vazões de pico, na Bacia do Alto Tietê em aproximadamente 100 anos, também é revela- dor dessa magnitude de transformação da paisagem física. Algo similar teria precedente apenas em quadros agudos de mudanças climáticas ou tectônicas. As mudanças reveladas nas tendências hidrodinâmicas, que passam a se assemelhar, em termos de tipologia de fluxos hídricos superficiais e balanço hidrológico de vertentes e cursos fluviais, a comportamentos típicos de meios áridos, é algo exemplar dessa magnitude, também alcançada em um século.

De acordo com BRUSDEN (1996) podemos classificar os eventos geomorfológicos, dentre outros tipos, como formativos e efetivos. Os eventos de natureza antrópica aqui trazidos podem ser considerados como formativos, na medida em que foram criados tipos e formas de relevo como, por exemplo, os terraços antrópicos e o canal artificial, que apresentarão longa persistência temporal. Também podem ser considerados efetivos, porque causaram mudanças instantâneas e de alta efetividade nos processos e nas taxas pré-urbanas como, por exemplo, a deposição de aterros e a redução da sinuosidade e alargamento do canal. Portanto, a magnitude das mudanças no sistema pré-urbano foi efetiva não somente ao ponto de criar novos depósitos sedimentares/registros estratigráficos, mas também ao ponto de criar novos processos, balanços e morfologias que só poderão ser novamente transformados através de novas intervenções antrópicas instantâneas e de alta magnitude ou através de eventos naturais extremos.

Isto ocorre e ocorrerá porque as mudanças ocorridas nos processos geomorfológicos superaram os limiares geomórficos que mantinham os sistemas pré-urbanos em equilíbrio dinâmico (SCHUMM 1977).

Diante disso, pode-se concluir que o ritmo e a magnitude das modificações impressas nos sistemas físicos, decorrentes da ação antrópica, são comparáveis a eventos naturais catastróficos. $\mathrm{O}$ emprego do termo "catastrófico" não se justifica aqui, apenas como força de expressão, mas remete à definição proposta por BRUNSDEN (1996), em que se considera a produção de uma certa subversão da ordem, com colapso do sistema anterior e sua eliminação, em que novos conjuntos de formas de relevo e novo estado de processos se impõem.

Com essa dinâmica de transformação, aumenta-se drasticamente a dependência de sistemas de engenharia, progressivamente redimensionados e com seus elevados custos de manutenção, 
além de aumentar a dependência de uma regularidade climática não compatível com os prognósticos científicos recentemente elaborados.

\section{AGRADECIMENTOS}

Ao CNPq (Bolsa de Produtividade PQ 2 da autora principal, processos 310764/2014-9 e 309715/2018-0), FAPESP (processo 2011/163965) e CAPES pelo apoio financeiro. Aos relatores da Revista do Instituto Geológico pelas sugestões apresentadas.

\section{REFERÊNCIAS BIBLIOGRAFICAS}

AB'SABER, A.N. 1957. Geomorfologia do sitio urbano de São Paulo. Ateliê Editoral, Cotia/ SP, 349 p. (Edição Fac-Similar 50 anos editada em 2007)

AB'SABER, A.N. 2004. São Paulo: Ensaios Entreveros. EDUSP, São Paulo, 522 p.

AMOS, J. 2018. BBC (British Broadcasting Corporation). Welcome to the Meghalayan Age - a new phase in history. Disponível em https://www.bbc.com/news/scienceenvironment-44868527. Acessado em 22 jan. 2019.

BATISTA, S.C. 2002. Conversa cartográfica: Processo de expansão urbana na metrópole paulistana e unidades geomorfológicas de média escala. Faculdade de Filosofia, Letras e Ciências Humanas, Universidade de São Paulo, São Paulo, Monografia de Conclusão de Curso, 176 p.

BERGER, A.R. 1996. The geoindicator concept and its application: an introduction. In: A.R. Berger \& W. J. Iams (eds.) Geoindicators: assessing rapid environmental changes in Earth systems. Rotterdam, A.A. Balkema, p. $1-14$.

BRITO, F.S.R. 1926. Melhoramentos do Rio Tietê em São Paulo. Seção de obras d' "O Estado de S. Paulo", São Paulo, 270 p. (Relatório).

BROWN, E.H. 1970. Man Shapes the Earth. Geographical Journal, 136: 74-85._http:// dx.doi.org/10.2307/1795683
BRUNSDEN, D. 1996. Geomorphological events and landform change. Z.Geomorph.N.F., 40(3): 273-288.

CAMPAGNOLI, F. 2002. A aplicação do assoreamento na definição de geoindicadores ambientais em áreas urbanas: exemplo na bacia do alto Tietê, SP. Escola Politécnica, Universidade de São Paulo, São Paulo, Tese de Doutorado, $192 \mathrm{p}$.

CARVALHO, D. 2006. Indicadores geomorfológicos de mudanças ambientais no sistema. Faculdade de Filosofia, Letras e Ciências Humanas, Universidade de São Paulo, São Paulo, Dissertação de Mestrado, 135 p.

CERTINI, G.; SCALENGHE, R. 2011. Anthropogenic soils are the golden spikes for the Anthropocene. The Holocene, 21(8): 1269-74. https://doi. org/10.1177\%2F0959683611408454

CHORLEY, R.J.; KENNEDY, B.A. 1971. Physical Geography: a systems approach. Prentice Hall International, London, 370 p.

CRUTZEN, P.J. 2002. Geology of Mankind. Nature, 415(23): 23. https://doi.org/10.1038/415023a

DAEE - DEPARTAMENTO DE ÁGUAS E ENERGIA ELÉTRICA. 1998. Plano diretor de macrodrenagem da bacia hidrográfica do Alto Tietê. São Paulo. Disponível em http://www.sigrh.sp.gov.br/sigrh/basecon/ macrodrenagem/index.html. Acessado em set. 2008 .

DAEE - DEPARTAMENTO DE ÁGUAS E ENERGIA ELÉTRICA. 2012. Terceiro Plano Diretor de Macrodrenagem da Bacia do Alto Tietê (PDMAT). São Paulo, 173 p.

DOUGLAS, I. 1983. The Urban Environment. Edward Arnold, Baltimore, Maryland, 229 p.

EMAE - EMPRESA METROPOLITANA DE ÁGUAS E ENERGIA. 2009. Controle de cheias do canal Pinheiros. Apresentação de slides arquivada no site do Instituto de Engenharia. São Paulo, Disponível em http:// ie.org.br/site/ieadm/arquivos/arqnot 2650 . pdf. Acessado em 28 abr. 2014. 
FELS, E. 1965. Nochmals: Anthropogene Geomorphologie. Petermanns Geographische Mitteilungen, 109: 9-15.

GOLOMB, B.; EDER, H.M. 1964. Landforms made by man. Landscape, 14: 4-7.

GOUDIE, A.S. 2013. The Human Impact on the Natural Environment: Past, Present, and Future. Wiley-Blackwell, Oxford, $7^{\text {th }}$ ed., $376 \mathrm{p}$.

GOUDIE, A.S; VILES, H.A. 1997. The Earth transformed: An introduction to human impacts on the environment. Blackwell, Oxford, $288 \mathrm{p}$.

GOUDIE, A.S; VILES, H.A. 2016. Geomorphology in the Anthropocene. Cambridge University Press, Cambridge, United Kingdom, New York, 380 p. https://doi.org/10.1017/ CBO9781316498910

GURNELL, A.M.; PEIRY, J.L.; PETTS, G.E. 2003. Using Historical Data in Fluvial Geomorphology. In: G.M. Kondolf \& H. Piégay (eds.) Tools in Fluvial Geomorphology. John Wiley \& Sons, Ltd., p. 77-101. https:// doi.org/10.1002/0470868333.ch4

HART, M.G. 1986. Geomorphology pure and applied. George Allen \& Unwin, London, $228 \mathrm{p}$.

HOOKE, J.M.; KAIN, R.J.P. 1982. Historical change in the physical environment: a guide to sources and techniques. Butterworth Scientific, London, Boston, Durban, Singapore, Sydney, Toronto, Wellington, $236 \mathrm{p}$.

\section{IUGS - INTERNATIONAL COMMISSION} ON STRATIGRAPHY. 2018. International Chronostratigraphic Chart. Disponível em http://www.stratigraphy.org/ICSchart/ ChronostratChart2018-08.pdf. Acessado em 22 jan. 2019.

JAMES, L.A.; MARCUS, W.A. 2006. The human role in changing fluvial systems: Retrospect, inventory and prospect. Geomorphology, 79(3-4): 152-171. https://doi.org/10.1016/j. geomorph.2006.06.017

JENNINGS, J. N. 1966. Man as geological agente. Australian Journal of Science, 28: 150-156.
LIMA, C.R. 1990. Urbanização e intervenções no meio físico na borda da bacia sedimentar de São Paulo, uma abordagem geomorfológica. Faculdade de Filosofia, Letras e Ciências Humanas, Universidade de São Paulo, São Paulo, Dissertação de Mestrado, 103 p.

LUZ, R.A. 2014. Mudanças geomorfológicas na planície fluvial do Rio Pinheiros, São Paulo $(S P)$, ao longo do processo de urbanização. Faculdade de Filosofia, Letras e Ciências Humanas, Universidade de São Paulo, São Paulo, Tese de Doutorado, 246 p.

LUZ, R.A.; RODRIGUES, C. 2015. Anthropogenic changes in urbanised hydromorphological systems in a humid tropical environment: River Pinheiros, Sao Paulo, Brazil. Zeitschrift für Geomorphologie Supplementary Issues, 59(2): 109-135. https://doi.org/10.1127/zfg_ suppl/2015/S-59207

MARSH, G.P. 1864. Man and Nature or, Physical Geography as modified by human action. John F. Trow, New York, 560 p.

MIETELSKI, J.W. 2010 Anthropogenic Radioactivity. In: D.A. Atwood (Ed.) Encyclopedia of Inorganic Chemistry. Chichester, John Wiley \& Sons.

MOROZ-CACCIA GOUVEIA, I.C. 2010. Da originalidade do sítio urbano de São Paulo às formas antrópicas: aplicação da abordagem da Geomorfologia Antropogênica na Bacia Hidrográfica do Rio Tamanduateí, na Região Metropolitana de São Paulo. Faculdade de Filosofia, Letras e Ciências Humanas, Universidade de São Paulo, São Paulo, Tese de Doutorado, 366 p. http://dx.doi.org/ 10.11606/T.8.2010.tde-31012011-123012

MOROZ-CACCIA GOUVEIA, I.C.; RODRIGUES, C. 2017. Mudanças morfológicas e efeitos hidrodinâmicos do processo de urbanização na bacia hidrográfica do rio Tamanduateí - Região Metropolitana de São Paulo. GEOUSP (Online), 21(1): 257-283. https://doi.org/10.11606/issn.2179-0892. geousp.2017.105342

NIR, D. 1983. Man, a geomorphological agent: an introduction to anthropic geomorphology. D. Reidel publishing Co., Keter publishing, Jerusalém, $165 \mathrm{p}$. 
PIVETTA, M. 2012. Da garoa à tempestade: Temporais se tornam mais frequentes e chuva aumenta $30 \%$ em São Paulo em 80 anos. Pesquisa Fapesp, 195. Disponível em http://revistapesquisa.fapesp.br/2012/05/11/ da-garoa-a-tempestade/. Acessado em 22 jan. 2019.

PRICE, S.J.; FORD, J.R.; COOPER, A.H.; NEAL, C. 2011. Humans as major geological and geomorphologicalagentsin theAnthropocene: the significance of artificial ground in Great Britain. Philosophical transactions. Series A, Mathematical, physical, and engineering sciences, 369(1938): 1056-1084. https://doi. org/10.1098/rsta.2010.0296

RODRIGUES, C. 1997. Geomorfologia aplicada: Avaliação de experiências e de instrumentos de planejamento fisico-territorial e ambiental brasileiros. Faculdade de Filosofia, Letras e Ciências Humanas, Universidade de São Paulo, São Paulo, Tese de Doutorado, 279 p.

RODRIGUES, C. 1999. On antropogeomorphology. In: IAG, REGIONAL CONFERENCE ON GEOMORPHOLOGY, Rio de Janeiro, Anais: 100-110.

RODRIGUES, C. 2004. A urbanização da metrópole sob a perspectiva da geomorfologia: tributo à leituras geográficas. In: A.F A. Carlos \& A.U. Oliveira (eds.) Geografias de São Paulo: representação e crise da metrópole. São Paulo, Contexto, p. 89-114.

RODRIGUES, C. 2005. Morfologia original e morfologia antropogênica na definição de unidades espaciais de planejamento urbano: Exemplo na metrópole paulista. Revista do Departamento de Geografia (USP), 17: 101-111. https://doi.org/10.7154/ RDG.2005.0017.0008

RODRIGUES, C. 2006. Sistemas Geomorfológicos e o Impacto da Urbanização na Metrópole de São Paulo. In: UGB, SIMPÓSIO NACIONAL DE GEOMORFOLOGIA - SINAGEO, 6, Goiânia, Guia de Excursão.

RODRIGUES, C. 2010. Avaliação do impacto humano da urbanização em sistemas hidrogeomorfológicos: Desenvolvimento e aplicação de metodologia na Grande São Paulo. Revista do Departamento de Geografia
(USP), 20: 111-125._https://doi.org/10.7154/ RDG.2010.0020.0008

RODRIGUES, C. 2013. Cem anos de urbanização e mudanças geomorfológicas na região metropolitana de São Paulo. (Relatório CNPq, bolsa produtividade).

RODRIGUES, C. 2014. Intervenções antrópicas e efeitos hidromorfodinâmicos em sistemas fluviais urbanizados de São Paulo em tempos de mudanças climáticas. (Relatório CNPq, bolsa produtividade, Fase 1, processo 309395/2011-9).

RODRIGUES, C. 2015. Atributos ambientais no ordenamento territorial urbano: o exemplo das planícies fluviais na metrópole de São Paulo. GEOUSP (Online), 19(2): 324-347. https://doi.org/10.11606/issn.2179-0892. geousp.2015.102805

RODRIGUES, C. 2018. Intervenções antrópicas e efeitos hidromorfodinâmicos em sistemas fluviais urbanizados de São Paulo em tempos de mudanças climáticas. (Relatório CNPq, bolsa produtividade, Fase 2, processo 310764/2014-9).

RODRIGUES, C.; COLTRINARI, L. 2004. Geoindicators of urbanization effects in humid tropical environment: São Paulo (Brazil) Metropolitan Area. In: IUGS, INTERNATIONAL GEOLOGICAL CONGRESS, 32, Florença, Anais: 976.

RODRIGUES, C.; MOROZ-CACCIA GOUVEIA, I.C.; LUZ, R. A.; MANTOVANI, J.; VENEZIANNI, Y. 2012. Plano de manejo da APA Várzea do Rio Tietê: diagnóstico do meio físico, sub-módulo recursos hídricos. Escola de Artes, Ciências e Humanidades (EACH-USP); Fundação Florestal (Governo do Estado de São Paulo). 142 p. (Relatório)

RUDDIMAN, W.F.; ELLIS, E.C.; KAPLAN, J.O.; FULLER, D.Q. 2015. Defining the epoch we live in. Science, 348(6230): 38-39. http:// dx.doi.org/10.1126/science.aaa7297

SCHUMM, S.A. 1977. The Fluvial System. Wiley, New York, 338 p.

SILVA, J. P. 2005. Expansão urbana e evolução geomorfológica em remansos de reservatórios: análise comparativa de duas bacias hi- 
drográficas em Guarapiranga, São Paulo. Faculdade de Filosofia, Letras e Ciências Humanas, Universidade de São Paulo, São Paulo, Dissertação de Mestrado, 122 p. http://dx. doi.org/10.11606/D.8.2006.tde-19072007101403

SILVA, J.P.; RODRIGUES, C. 2018. Avaliação histórica de taxas de colmatagem e sua relação com a evolução da urbanização em bacias hidrográficas pareadas em Avaliação histórica de taxas de colmatagem e sua relação com a evolução da urbanização em bacias hidrográficas pareadas em Guarapira. Geousp - Espaço e Tempo, 22(1): 172-190. http://dx.doi.org/10.11606/issn.2179-0892. geousp.2018.119458

SILVA DIAS, M.A.F.; DIAS, J.; CARVALHO, L.M.V.; FREITAS, E.D.; SILVA DIAS, P.L. 2013. Changes in extreme daily rainfall for São Paulo, Brazil. Climatic Change, 116(34): 705-722. https://dx.doi.org/10.1007/ s10584-012-0504-7

SIMAS, I.T.H. 2017. Análise retrospectiva de inundação na bacia do Rio Aricanduva, São Paulo. Faculdade de Filosofia, Letras e Ciências Humanas, Universidade de São Paulo, São Paulo, Dissertação de Mestrado, 168 p. http://dx.doi.org/10.11606/D.8.2017.tde21072017-162915

SLAYMAKER, O.; SPENCER, T.; EMBLETONHAMANN, C. 2009. Geomorphology and global environmental change. Cambridge University Press, New York, 468 p._https:// doi.org/10.1017/CBO9780511627057

SMITH, B.D.; ZEDER, M.A. 2013. The onset of the Anhropocene. Anthropocene, 4: 8-13. https://doi.org/10.1016/j.ancene.2013.05.001

STEFFEN, W.; SANDERSON, R. A.; TYSON, P.D.; JÄGER, J.; MATSON, P.A.; MOORE III, B.; OLDFIELD, F.; RICHARDSON, K.; SCHELLNHUBER, H.-J.; TURNER, B.L.; WASSON, R.J. 2004. Global Change and the Earth System. Springer, Berlin, Heidelberg, New York, 336 p.

STEFFEN, W.; CRUTZEN, P.J.; MCNEILL, J.P. 2007. The Anthropocene: Are Humans Now Overwhelming the Great Forces of Nature? Ambio, 36(8): 614-621.
SZABÓ, J.; DÁVID, L.; LÓCZY, D. (eds). 2010. Anthropogenic geomorphology: A guide to man-made landforms. Springer, Dordrecht, Heidelberg, London, New York, 250 p._http:// dx.doi.org/10.1007/978-90-481-3058-0

THOMAS, W.L. 1956. Man's role in changing the face of the Earth. Univ. Chicago Press, Chicago, $1193 \mathrm{p}$.

TOY, T.J.; HADLEY, R.F. 1987. Geomorphology and reclamation of disturbed lands. Academic press Inc., Orlando, $480 \mathrm{p}$.

TRAVASSOS, L.R.F.C. 2008. Macrodrenagem e expansão urbana na bacia do Alto Tietê. In: Tietê Vivo - Fórum de difusão científica para inovações de pesquisa e extensão, USP. Disponível em https://tietevivo.files.wordpress. com/2008/06/luciana-travessos.pdf. Acessado em 22 jan. 2019.

TRIMBLE, S.W. 1974. Man-induced Soil Erosion on the Southern Piedmont. Soil Conservation Society of America, Ankeny, Iowa, $180 \mathrm{p}$.

TRIMBLE, S.W. 2008. The use of historical data and artifacts in geomorphology. Progress in Physical Geography: Earth and Environment, 32(1): 3-29. https://doi. org/10.1177/0309133308089495

TURNER, B.L.; KASPERSON, R.E.; MEYER, W.B.; DOW, K.M.; GOLDING, D.; KASPERSON, J.X.; MITCHELL, R.C.; RATICK, S.J. 1990. Two types of global environmental change: definitional and spatial - scale issues in their human dimensions. Global Environmental Change, 1(1): 14-22. https://doi.org/10.1016/09593780(90)90004-S

VENEZIANI, Y. 2014. A abordagem da geomorfologa antropogênica e de modelagens hidrológica e hidráulica na bacia do Córrego Três Pontes (SP) para determinação de picos de vazão e da vulnerabilidade a inundações. Faculdade de Filosofia, Letras e Ciências Humanas, Universidade de São Paulo, São Paulo, Dissertação de Mestrado, 298 p. http://dx.doi.org/10.11606/D.8.2014.tde30112015-133046 
WOEIKOF, A. 1901. De l'influence de l'homme sur la terre. Annales de Géographie, 10(50): 97114. https://doi.org/10.3406/geo.1901.4871

ZALASIEWICZ, J.; WILLIAMS, M.; HAYWOOD, A.; ELLIS, M. 2011. The Anthropocene - a new epoch of geological time. Philosophical Transactions of the Royal Society A: Mathematical, Physical and Engineering Sciences, 369 (1938): 835-841. https://doi. org/10.1098/rsta.2010.0339

ZALASIEWICZ, J.; WATERS, C.N.; WILLIAMS, M.; BARNOSKY, A.D.; CEARRETA, A.;
CRUTZEN, P.; ELLIS, E.; ELLIS, M.A.; FAIRCHILD, I.J.; GRINEVALD, J.; HAFF, P.K.; HAJDAS, I.; LEINFELDER, R.; MCNEIL, J.; ODADA, E.O.; POIRIER, C.; RICHTER, D.; STEFFEN, W.; SUMMERHAYES, C.; SYVITSKI, J.P.M.; VIDAS, D.; WAGREICH, M.; WING, S.L.; WOLFE, A.P.; AN, Z.; ORESKES, N. 2015. When did the Anthropocene begin? A midtwentieth century level is stratigraphically optimal. Quaternary International, 383: 196-203. https://doi.org/10.1016/j. quaint.2014.11.045

\section{Endereço dos autores:}

Cleide Rodrigues, Yuri Veneziani e Iury Tadashi Simas - Departamento de Geografia, Faculdade de Filosofia, Letras e Ciências Humanas, Universidade de São Paulo/USP, Av. Prof. Lineu Prestes, 338 Butantã, CEP 05508-000, São Paulo, SP.E-mails: cleidrig@usp.br, yuri.veneziani@usp.br, iurysimas@ usp.br

Isabel Cristina Moroz-Caccia Gouveia - Faculdade de Ciências e Tecnologia, campus de Presidente Prudente, Universidade Estadual Paulista/UNESP, Rua Roberto Simonsen, 305, Centro Educacional, CEP 19060-900, Presidente Prudente, SP. E-mail: isabel.moroz@unesp.br

Rodolfo Alves da Luz - Universidade Federal do Tocantins (UFT), Laboratório de Geoprocessamento, Rua 03, Quadra 17, Lote 11, s/nº, Setor Jardim dos Ipês, Bloco IV, CEP 77500-000, Porto Nacional, TO.E-mail: rodolfodaluz@uft.edu.br

Juliana de Paula Silva - Universidade Estadual de Maringá, Av. Colombo, 5790 - Zona 7, CEP 87020-900, Maringá, PR. E-mail: jpsilva@uem.br

Artigo submetido em 26 de janeiro de 2019, aceito em 23 de abril de 2019. 